\title{
Comparative analysis of the structure of coals of different stages of metamorphism according to ${ }^{13} \mathrm{C}$ NMR data
}

\author{
(C) Sergey Yu. Lyrshchikov, ${ }^{*+}$ and Larisa V. Sotnikova \\ Federal Research Center of Coal and Coal-Chemistry of SB RAS. \\ Soviet Ave., 18. Kemerovo, 650024. Kemerovo Region. Russia. \\ Phone:+7 (3842) 363739.E-mail: serstud@mail.ru
}

\begin{abstract}
*Supervising author; ${ }^{+}$Corresponding author Keywords: solid-state ${ }^{13} \mathrm{C}$ NMR spectroscopy, coals, stage of metamorphism.
\end{abstract}

\begin{abstract}
In this paper, the method of cross-polarization with magic angle rotation and decoupling from protons (CPMAS) ${ }^{13} \mathrm{C}$ NMR spectroscopy obtained quantitative data on the distribution of carbon over structural fragments and calculated the degree of aromaticity $\left(f_{a}\right)$ of some coal samples from various Siberian deposits of a wide range of metamorphism. All the coals used in the work were characterized by standard methods (proxymate and ultimate analysis). The optimal parameters of the pulse program for recording the spectra of coals have been determined. To obtain quantitative data, the spectra were simulated. The spectrum model included from 9 to 13 components, depending on the stage of coal metamorphism. The dependences of the degree of aromaticity and the sum of oxygen-containing functional groups on the stage of coal metamorphism were constructed. The results obtained show that the structure of coals regularly changes depending on the stage of their metamorphism. The revealed relationships of the structure and properties of coals, together with the parameters of their reactivity, can ensure the safe behavior of coals in the processes of mining and processing, as well as in determining possible ways of using the studied coal samples as a valuable chemical raw material.
\end{abstract}

\section{References}

[1] A.D. Alekseev, E.V. Ulyanova, T.A. Vasilenko. Possibilities of NMR in the study of physical processes in buried coals. Advances in physical sciences, instruments and research methods. 2005. Vol.175. No.11. P.1217-1232. (russian)

[2] D. Massiot, F. Fayon, M. Capron, I. King, S. Le Calvŭ, B. Alonso, J-O. Durand, B. Bujoli, Z. Gan, G. Hoatson. Modelling one- and two-dimensional Solid State NMR spectra. Magnetic Resonance in Chemistry. 2002. Vol.40. P.70-76.

[3] A.M. Gyulmaliev, G.S. Golovin, T.G. Gladun. Theoretical foundations of coal chemistry. Moscow: Publishing house MGGU. 2003. 556p. (russian)

[4] H. Sfihi, M. Quinton, A. Legrand, S. Pregermain, D. Carson, P. Chiche. Evaluation of the aromaticity in French coals by $13 \mathrm{C}-1 \mathrm{H}$ cross polarization, magic angle spinning and dipolar dephasing nuclear magnetic resonance spectroscopy. Fuel. 1986. Vol.65. P.1006-1010.

[5] E. Furimsky, J. Ripmeester. Characterization of Canadian coals by nuclear magnetic resonance spectroscopy. Fuel processing technology. 1983. Vol.7. P.191-202.

[6] N. Russel, M. Wilson, R. Pugmire, D. Grant. Preliminary studies on the aromaticity of Australian coals: Solid state n.m.r. techniques. Fuel. 1983. Vol.62. P.601-605. 